\title{
Effect of Professionalism of Work and Social Network on Teachers in Private Schools; Case Study in Indonesia
}

\author{
${ }^{1}$ Yohanes Arianto Budi, ${ }^{2}$ Erwin Bramana Karnadi, and ${ }^{3}$ Fransiskus X Lara Aba \\ ${ }^{1,2,3}$ Faculty Economics \&amp- Business- Atma Jaya Catholic University of Indonesia \\ 1 yohanes.arianto@atmajaya.ac.id, ${ }^{2}$ Erwin.karnadi@atmajaya.ac.id, \\ 3 fransiskus.lara@atmajaya.ac.id
}

\begin{abstract}
This study aims to prove whether there is a significant effect of Professionalism, Creativity and Social Network on teacher performance, which is mediated by the Self Efficacy variable. This research was conducted in five private schools in Jakarta Indonesia involving several teachers who were still actively teaching. A total of 240 questionnaires were distributed and 183 questionnaires were returned and could be processed, so the sample of 183 respodent. Data processing was carried out using Path Analysis. The results from this study indicate that there is a positive and significant influence between Professionalism and Performance. Professionalism has a direct influence (0.201) and indirect influence on Performance (0.110) which means it can be mediated by Self Efficacy. The Social Network variable shows an indirect effect on teacher performance (0.03), which means it can be mediated by the Self Efficacy variable. The results effect on teacher performance (0.028) which also means that it can be mediated by Self Efficacy. While the Self Efficacy variable itself has a direct influence (0.203) on teacher performance. Overall, mediation is needed for this research model for each variable.
\end{abstract}

Keywords: Professionalism, Social Networking, Creativity and Performance

JEL Classification Code: M10, M12, M14

\section{Introduction}

One way to improve the quality of Human Resources (HR) in a country must begin with a good and professional education system. Improving the quality of education is a matter that must get top priority. This is because education is the beginning and foundation in shaping the superior quality of human resources. Quality of human resources can win the competition in an era of globalization that is unavoidable. All countries are currently preparing an education system that enables young people to succeed in global competition. Currently competing through the quality of HR or often referred to as competing through people is the main theme in every discussion and discussion about Human Resources, (Bohlander, Snell, 2010). Although the curriculum used is the same, the teaching and learning process has high dynamics. Many private schools that excel, have a national reputation because of the quality of their graduates. Quality and reputation not only concerned physical facilities and curriculum, but also Human Resources.

Researchers can the influence between creativity, professionalism and social networks on the performance of teachers because the three variables are closely related to performance and must be developed and maintained properly. Maintaining and improving performance is not only through extrinsic incentives, the performance of a teacher must continue to be improved through high professionalism, a good social network and creative teaching that must continue to be pursued. 


\section{Literature Review}

Research on how creativity, professionalism and social networks have been carried out and the results are very significant for performance. In this study, tried to analyze the effect of these three variables on teacher performance based on the actual performance assessment of the institutions they worked for. Performance becomes a quantitative and qualitative benchmark of the outcome or achievement of a teacher who includes technical and non-technical aspects related to his work.

\subsection{Professionalism}

Schermerhorn (2010), said that professionalism required a responsibility such as adding added value to the company where we work, personally responsible for the task, becoming a leader who upholds ethical values, promotes the principles of justice and equality in the workplace, honest, protect the rights of others, trying to reach a high standard of work and always trying to improve capabilities. A professional teacher will prioritize these things and prioritize the improvement of their students' abilities by upholding moral principles and honesty. A good teacher must be able to properly separate work that is directly related to academic matters with other matters outside of work that have the potential to disrupt their performance.

\subsection{Professionalism and Performance among Educators}

One important aspect of this research is the key to the value of a profession as an educator, namely professionalism. Some literature states that without the support of high enthusiasm and professionalism, it is impossible for an educator to achieve optimal performance. However, it is also the case with other professions, but this research tries to see from a very important profession, namely educators or teachers.

Professionalism among teachers must be supported by a good organizational situation or climate. It is necessary to foster good collaboration or collaboration among educators with a culture of trust or high trust and accountability so that collegial professionalism can be achieved (Tan Charleen, Tee Ng, 2012). Trust culture must be the center of all activities and cooperation in an educational organization or institution. Without high trust among educators, the spirit of professionalism will be difficult to develop professionalism and accountability among teachers. At present, a teacher must adjust the way of teaching with the conditions of students, use data efficiently to monitor learning needs, work together (collaboration) with fellow teachers, share knowledge and help each other to be reliable as professionals (Agezo, Kwadzo, 2009).

Things to work together or collaboration are important findings in every research on professionalism that leads to performance. Educators must maintain good relationships with fellow educating colleagues, have sensitivity to change and have a leadership spirit in accordance with their careers and have good priority urgency in order to be able to answer the challenges of being quality educators (Day, Smethem, 2009). Basically, teachers or educators must work together, learn from fellow teachers, and have clear standards about practical things about their work. In addition, you must also review what has been done. This will help teachers improve their professionalism (Wildy, Wallace, 1998).

\subsection{Social Network}

Another factor that can support the success of a teacher's current job is good networking. We all know that having a network can add insight, knowledge and change one's perspective to a more advanced direction. Social networking or social network, allows a teacher to obtain information on his work or duties, discuss with colleagues, and make it easier to find solutions for the problems he experienced as educators. There are no harm, mutual friendship and discussion with fellow teachers from other schools. Another important thing that can support the success of an educator's task is a high sense of optimism and confidence in teaching. Optimism and self-confidence are the basis of important behavior as an educator and leader in the class. Optimism leads to a positive way of looking at something and hopes that things will go well (Daft, 2015). 


\subsection{Self Efficacy}

Likewise, the self-confidence that leads to a sense of confidence, knowing and trusting (knowing and trusting) about their duties. In the end, self-confidence will be related to self-efficacy, which is a very strong belief that someone will be able to complete his task well. Self-confidence is related to self-efficacy, which accomplishes a specific task or outcome (Daft, 2015). Self-efficacy is very important because it also includes motivation and is a specific part of self-esteem it is an individual belief about the likelihood of successfully completing a specific task. You can be high in self-esteem yet have a feeling of low self-efficacy about performing certain tasks, such as public speaking, (Schermerhorn, 2005). The explanation above indicates that self-efficacy is closely related to self-esteem, where Schermerhorn explained that it could happen that people feel proud when speaking in public, but do not feel confident of their abilities.

Previous research conducted by Cadima, Ojeda and Monquet (2012), states that there is a very close correlation between social networks and performance within the learning community among $\mathrm{PhD}$ program students in Spanish Catalonia and Leiria Portugal. The results for this study did not examine the teacher respondents or educators, but the methods and analysis could be used to become one of the references in this study because it involved the teaching-learning process. The Doctoral program students in these two countries feel their performance is closely related to their ability to build social networks.

\subsection{Creativity}

Basically, creativity is the ability to create something new that has added value and can be used for certain things more effectively and efficiently. Creativity does not only refer to a product, but also the methods, techniques and methods of teaching. Schermerhorn (2010), said that ... Creativity is the generation of novel ideas or unique approaches that solve a problem or craft an opportunity. From this definition, it is clear that there are keywords that are important to remember, namely a novel idea and a unique approach. Teachers must have a way of teaching that is not only communicative but also creative. This is based on the condition of students who are not necessarily at the same level intelligently. Furthermore, Schermerhorn also explained that there are three things that are triggers of creativity, namely the experience of the task, motivation in completing the task and the ability to be creative.

\subsection{Creativity and Performance}

Research (Sen Woo, Lee and Tsai, 2012) refers to the creativity variable that positively and significantly shows its effect on performance. Even further increasing self-efficacy turned out to increase creativity among athletes, which in turn improved team performance and personal performance. In the end, it does lead to teacher performance. Therefore, the development of attitudes, behavior and expertise as a teacher must continue to be improved. Even more important is how to foster good cooperation among teachers, even though the fields are different but good cooperation will increase high self-confidence and improve the self-efficacy of teachers in work.

This variable is proven to be a mediator who needs to be considered by managers of educational institutions because it has a significant effect on improving teacher performance (Chieh Peng, Wuu, Hui, Chang, 2013). Although this study prioritizes the success of work performance teams, it can be believed that organizational climate factors and self-efficacy can mediate variables on performance. This indicates that self-efficacy must be developed among teachers in their career paths because it is proven to be able to improve performance towards a higher direction and this is something very valuable (Moran, Hoy and Hoy, 1998).

\subsection{Performance}

In general, performance refers to work results, which are outcomes that can be measured by certain methods. As a teacher/educator performance appraisal always uses standard and has assessment criteria from various perspectives. According to Aguinis (2013), performance standards, is a measurement used to evaluate how well an employee completes his work. Measuring performance using predetermined standards will facilitate the evaluation process among educators. The standards made are always linked to the achievement criteria of the assignments of each teacher. 
It also aims to monitor the development of an employee, because each assessment period criterion can be added or increased so that each employee always improves and directs its performance in the process of continuous improvement. In addition to aiming to determine the amount of salary, bonuses, promotions and identifying which employees are good and not good, performance appraisals also contribute high in terms of employee development or long-term goals.

\section{Research Methods}

\subsection{Sampling Method}

The populations in this study were private school teachers in DKI Jakarta who worked both permanent and honorary teachers. According to Fraenkel \& Wallen (2006), the minimum sample that can be accepted for correlational research is not less than 30. Data collection in this study was carried out by according to Istijanto (2008), convenience, sampling is a technique for determining research samples by attracting members to the based on their ease of meeting or the availability of certain members in the population. Respondents were chosen because of their existence at the time and place when the research was conducted. To measure the professionalism used a measuring instrument developed by Carter, Heselgreeves, Rothwell, Grampton, Bufford, Mc Lachlan and Illing, in his study entitled "Measuring Professionalism as a Multidimensional Construct," Final Report of The HCPC, October 2015.

Meanwhile, for Social Network variables, a measurement tool developed by Van's der Gaag and Snijders was used, in a study entitled. Creativity variable was measured using a questionnaire developed by Carson, Peterson and Higgins, in a study entitled "Reliability, Validity and Factor Structure of the Creative Achievement Questionnaire," All Right of Reproduction in any form is reserved with a few modifications. For performance variables, data is obtained directly from the school, in the form of teacher performance reports and assessment criteria filled in by the leader or the Principal.

\subsection{The Structural Equation of the Relationship Model Between Variables}

Broadly speaking, this study analyzes and identifies the impact of the variables' Creativity, Professionalism and Social Network on the performance of private school teachers in the Jakarta area. Which the Self Efficacy variable can mediate the influence of Creativity, Professionalism and Social Network on the performance of private school teachers in the Jakarta area. The results of this study are also expected to be able to provide recommendations on the impact of the influence and mediation of research variables as the basis and direction of school policies to improve the Professionalism, Creativity and Social Network capabilities of teachers who will ultimately improve performance.

The results of this study are expected to be useful as a contribution of thought, especially for managers of private schools or institutions that manage private schools regarding the importance of creativity, professionalism and the ability of teachers' social networks in improving performance. In addition, this study also identifies one important variable, namely self-efficacy as a mediating variable. Self-efficacy is basically a belief in yourself that each teacher can carry out every task and responsibility. So high confidence will increase one's confidence and will ultimately improve performance. This study will answer whether the variables of self-efficacy can mediate the influence of other variables on performance. 


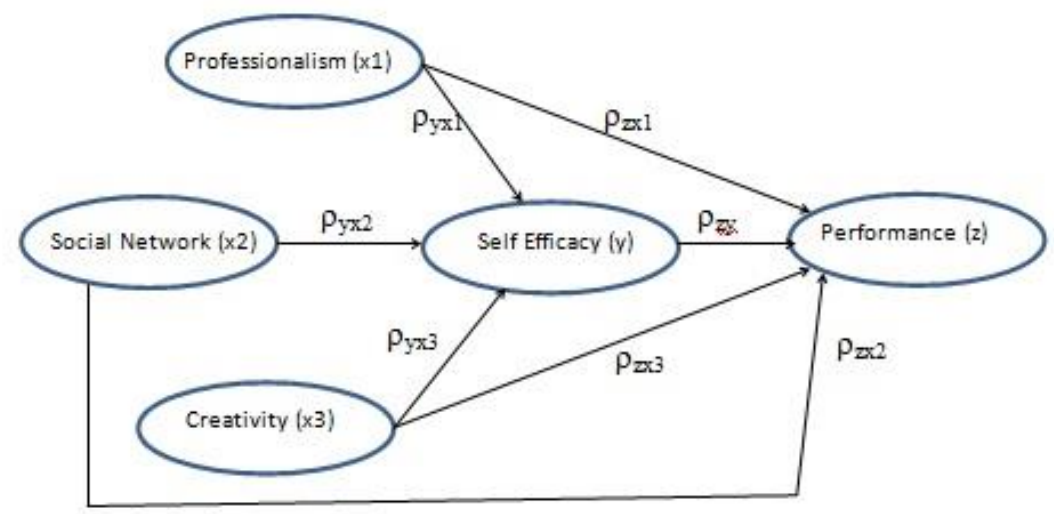

Picture. 3. 1 Research Model

The structural equation into the relationship model between variables

There are two kinds of structural equations for existing models:

- structural equations 1 . Self Efficacy $(y)=\rho y x 1+\rho y x 2+\rho y x 3+\varepsilon$

- Structural equation 2: Performance $(Z)=\rho x 1+\rho z x 2+\rho z x 3+\rho z y+\varepsilon$

Where: x1 - Professionalism x2 - Social Network x3 - Creativity

y - Self Efficacy z - Performance

\section{Results}

In carrying out its duties, a professional teacher will understand how to do education, supervision and how to communicate. This all involves emotions that must also be managed properly. Emotions will affect someone's feelings caused by an interaction with someone or something, (Robbins, Judge, 2017). Therefore, various ways are carried out by the management or educational institutions or school management to be able to improve not only the quality of the curriculum but also the quality of educators.

At present, educators in primary, secondary and high schools in Indonesia must have at least a Bachelor degree. This is a minimum demand in order to increase the competitiveness of human resources because the Bachelor level has a standard that is considered sufficient to act as an educator. In addition, management or educational institutions continue to strive to provide training for educators who are related to their duties. This training certainly seeks to reduce the gap between the expertise that teachers have today and what they should ideally have.

From the results of the collected and processed questionnaires, 183 questionnaires were collected consisting of 81 female respondents and 102 male respondents. Respondents with a work period of fewer than five years amounted to 39 people (21\%), who worked between 5 to 10 years totalling 32 people (18\%), who worked for 10 years as many as 112 people $(61 \%)$. The respondents who taught in elementary and kindergarten numbered 59 people (32\%), who taught on the junior high school level were 67 people (37\%), and those who taught on the high school level were 57 people $(31 \%)$.

The average level of education among the respondents is $\mathrm{S} 1$ graduates totalling 171 people (93\%) and S2 and S3 totalling 12 people (7\%). In terms of employment status, of respondents (151 people) were permanent employees, and (32 people) were honorary teachers. 123 respondents $(73 \%)$ were married, and the remaining 49 people $(27 \%)$ were single. 
3.1. Table Path Analysis: structural equation 1. Self Efficacy $(y)=\rho y \times 1+\rho y x 2+\rho y x 3$

\begin{tabular}{|l|l|l|l|l|l|}
\hline \multicolumn{6}{|c|}{ Model Summary $\mathbf{b}^{\mathbf{b}}$} \\
\hline Model & $\mathrm{R}$ & R Square & Adjusted R Square & $\begin{array}{l}\text { Std. Error of the } \\
\text { Estimate }\end{array}$ & Durbin-Watson \\
\hline 1 &, $738^{\mathrm{a}}$ &, 545 &, 537 &, 50098 & 2,152 \\
\hline
\end{tabular}

a. Predictors: (Constant), Creativity, Profesionalism, Social Network

b. Dependent Variable: Self Efficacy

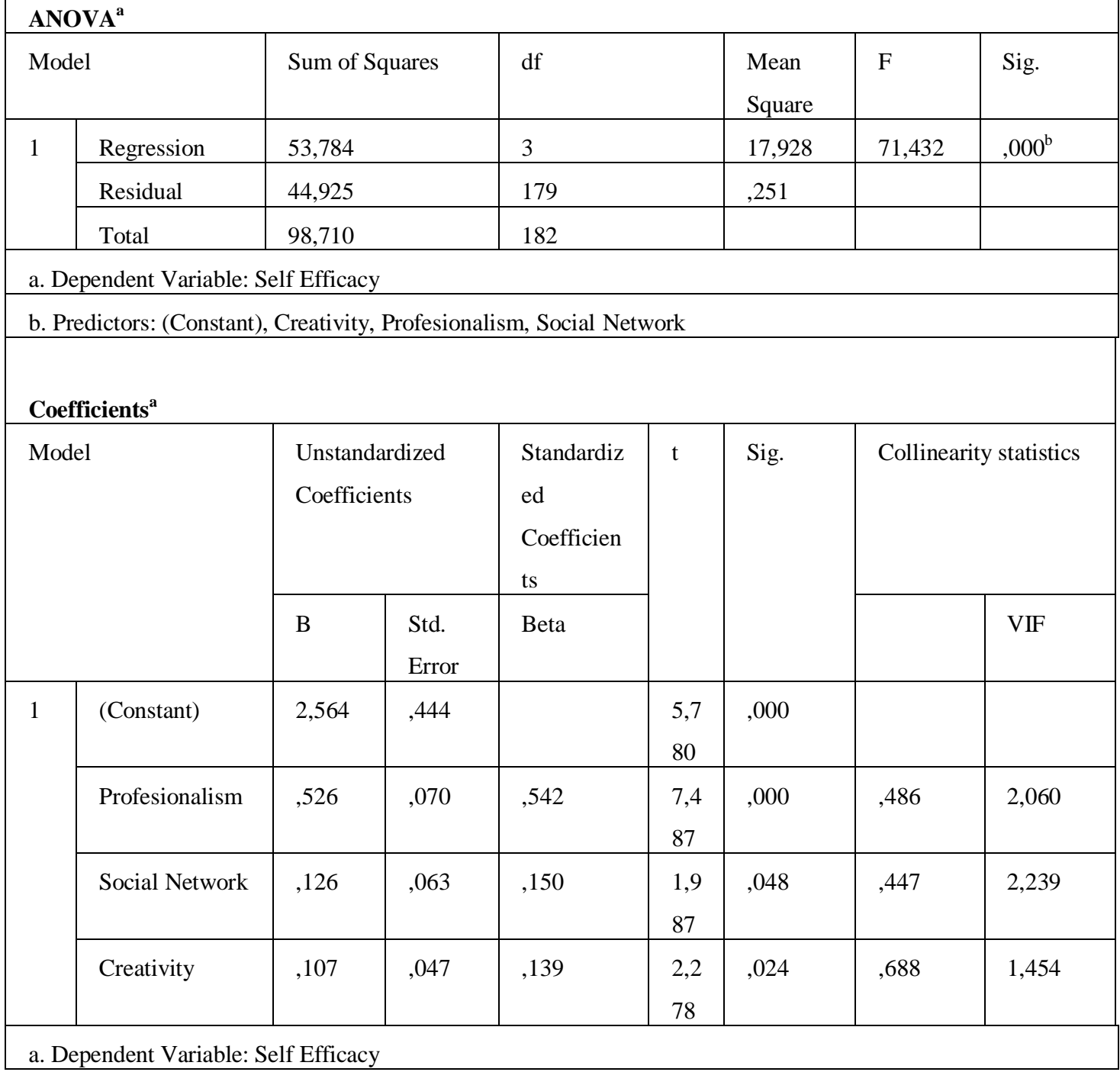

\section{Conclusion:}

For $\alpha=0.10$, all variables are significant:

One of the human resources which had a role to take part in this system is the teachers who carry out their duties as educators. These teachers will later come from direct contact with students, starting from the level of elementary, secondary education to a high level. The teachers directly take part in this process, even though they are also supported by a curriculum that supports the teaching and learning process so that later produce qualified graduates.

Being a professional teacher certainly requires some important things, this will greatly determine the success as a teacher in carrying out his duties as an educator. Tasks as educators can be classified as jobs that require interaction and the ability to socialize well, this is because a teacher 
must be able to carry out several functions at once, including education, supervision and communication.

Table 3.2. Structural equation 2: Performance $(Z)=\rho z x 1+\rho z x 2+\rho z x 3+\rho z y$

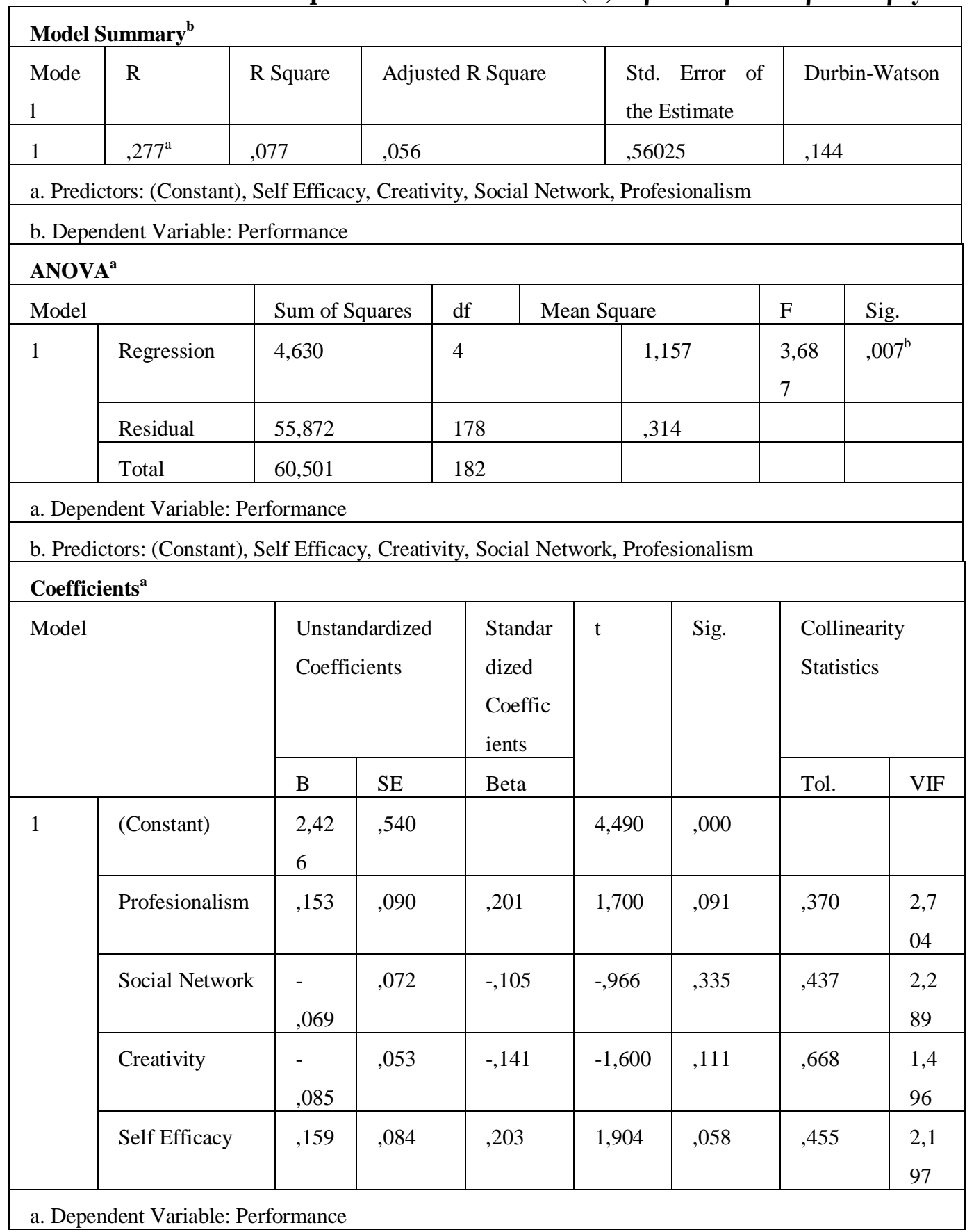

\section{Conclusion:}

For $\alpha=0.10$, significant variables are Professionalism and Self Efficacy. Social Network uncreativity is not significant.

Of course, the target of each training is to overcome the problem in the short term, but it is expected to be able to equip the teachers so that they can be more professional in carrying out their duties. The purpose of training is to master the abilities, skills and behaviours that support one's activities by day. The job of being an educator is indeed complex. This is related to the relationship of an educator to the institution where he works, fellow educators and students. A teacher is required to be professional, which means upholding work ethic, being creative and having good relationships and networking. Creativity certainly starts with a problem about how to develop teaching methods so 
that they are more effective and efficient. This aims to get maximum results from the students, through the appropriate teaching and learning process.

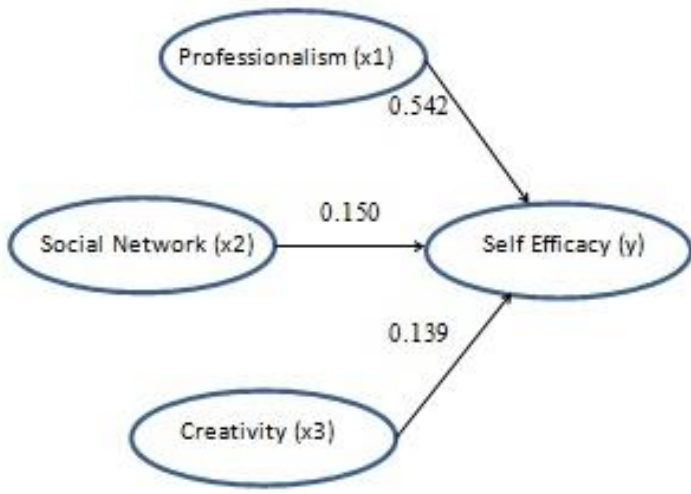

Figure 3.2. : Structural equations 1. Self Efficacy $(y)=\rho y x 1+\rho y x 2+\rho y x 3$

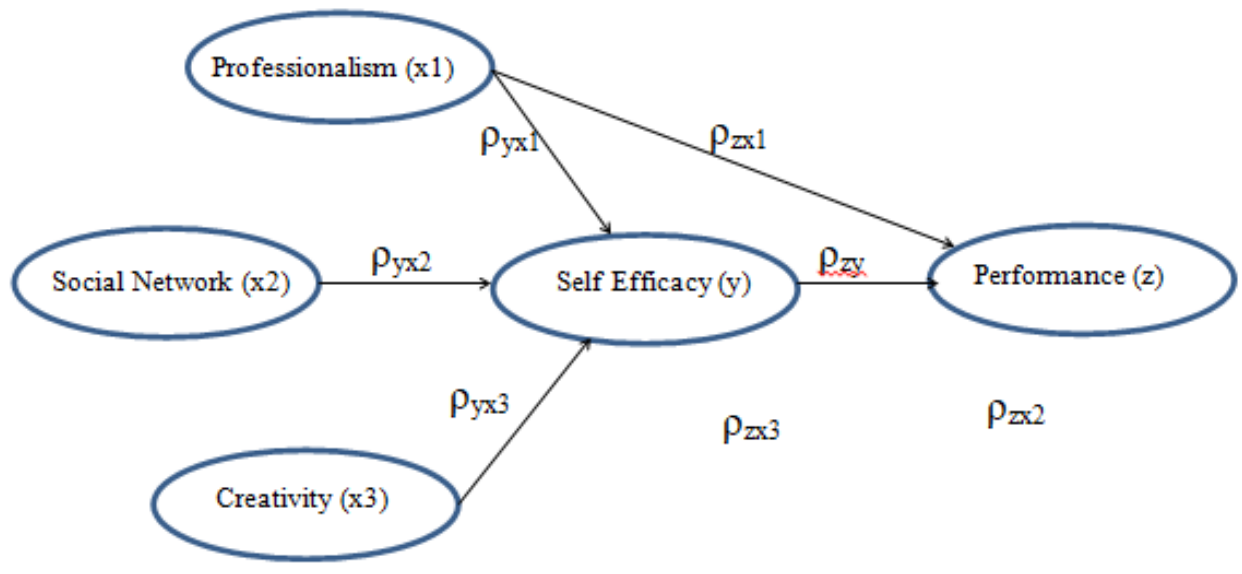

Figure 3.4. The final result

1. Effect of $\mathrm{x} 1$ - Professionalism on $\mathrm{z}$ - Perfomace

Direct effect $=0.201$

Indirect effect $=0.542 \times 0.203=0.110$

Total effect $=0.311$

2. Effect of $\mathrm{x} 2$ - Social Network on $\mathrm{z}$ - Performance

Indirect effect $=0.150 \times 0.203=0.030$

3. Effect of $\mathrm{x} 3$ - Creativity on $\mathrm{z}$ - Performance

Indirect effect $=0.139 \times 0.203=0.028$

4. Effect of y - Self-Efficacy on $\mathrm{z}$ - Performance

Direct effect $=0.203$

Performance needs to be assessed because it can be used as a guide for administrative matters such as salaries, bonuses and other incentives, as well as for development and other strategic goals (Aguinis, 2014). Actual performance-based performance assessment in the view of researchers is more meaningful than the performance based on employee perceptions. This is caused by the existence of better objectivity because in the process of performance appraisal, the boss should judge the subordinates. This performance inquiry system is the standard system to date and at the time this research was conducted. Actual performance data became an important and meaningful thing. 


\section{Conclusion}

The factors that influence the performance based on rank are Professionalism, Self Efficacy, Social Network, and Creativity. This research shows that there is a positive and significant influence between Professionalism and Performance. Professionalism has a direct influence (0.201) and indirect influence on Performance (0.110) which means it can be mediated by Self Efficacy. The Social Network variable shows an indirect effect on teacher performance (0.03), which means it can be mediated by the Self Efficacy variable. The results with other studies show that the creativity variable has an indirect effect on teacher performance (0.028) which also means that it can be mediated by Self Efficacy. While the Self Efficacy variable itself has a direct influence (0.203) on teacher performance. Overall, mediation is needed for this research model for each variable. In general, mediation is still needed for all variables studied.

The important managerial implication for this study, that although there are direct or indirect influences, all variables contribute significantly to teacher performance. Professionalism must be improved, feeling confident in the teacher's ability is also something that needs to be owned. As teachers dealing with millennial, teachers must also be able to use social media and other media devices such as the Internet to expand networking and friendship among teachers. This is important because, in the millennial era, networking is a valuable investment. The last is creativity, which is an important element in developing teaching methods that include good delivery techniques and processes.

\section{References}

[1] Aguinis. Herman, Performance Management, Pearson Education Limited, third edition, Indiana University, USA, Copyright, (2013)

[2] Agezo. Kwadzo, School reforms in Ghana: A Challenge to teacher quality and professionalism, Ife Psychologie, Ile_Lfe Volume, Florida A and M University, 17(2)(2009) 40 - 64, https://doi.org/10.4314/ifep.v17i2.45302

[3] Bandura, Guide for Constructing Self Efficacy Scales, Teachers Efficacy Scale. Self Efficacy Beliefs of Adolescents, (2006), pp. 307-337,

[4] Bohlander. Snell, Principles of Human Resource Management, International edition, South Western Cengage Learning, 15th edition, (2010) page 4.

[5] Cadima. Ojeda dan Monquet, Social Network and Performance in Distributed Learning Communities Education, Technology and Society Journal, 15(4)(2012), 296-304.

[6] Carson, Peterson \& Higgins, Reliability, Validity and Factor Structure of the Creative Achiement Questionnaire, Creative Research Journal, 17(1)(2005), 37-50, https://doi.org/10.1207/s15326934crj1701_4

[7] Carter, et all, Measuring Professionalism as a Multidimensional Construct, Final Report of The HCPC, Professionalism and Conscientiousnes in Health Care, Durham University, Newcastle University, (2015

[8] Chieh. Peng, Wuu, Hui, Chang, Exploring Team Climate and Performance : Mediating effects of Cooperation and Team Efficacy, Proceeding of ASBBS, 20(1)(2013), ASBBS Annual Conference, Las Vegas,

[9] Fraenkel. J. R., Wallen. N. E., \& Hyun. H. H., How to design and evaluate research in education. 8th Edition. New York: McGraw-Hill, (2012)

[10] Kaufman James, Counting The Muses : Development of The Kaufman Domains of Creativity Scale (KDOCS), Journal of Psychology of Aesthetics, Creativity and The Art. 6(4)(2012), 298-308., https://doi.org/10.1037/a0029751 
[11] Daft. Richard, The Leadership Experience, Owen Graduate School of Management -with assistance of Paticia Lane. Vanderbilt University, sixth edition, Cengage learning, (2015), pp. 38-39.

[12] Day \& Smethem, The Effects of reform: Have teachers really lost their sense of professionalism ?, Journal education of change, 10(2-3)(2009), 141-157, https://doi.org/10.1007/s10833-009-9110-5

[13] Istijanto, Aplikasi Praktis Riset Pemasaran. Jakarta: Gramedia Pustaka Utama, (2008)

[14] Moran, Hoy, \& Hoy, Teacher Efficacy: Its Meaning and Measure, Review of Educational Research, 68(2)(1998),479, https://doi.org/10.2307/1163531

[15] Noe, Raymond, Employee Training and Development, Mc Graw Hill International Edition, sixth edition, Mc Graw Hill Education,(2013) pp. 8.

[16] Robbins \& Judge, Organizational Behavior, Global Edition, Pearson seventeenth edition, Pearson education limited, Edinburg gate Harlow,(2017), pp.141.

[17] Schermerhorn, Hunt, Osborn, Organizational Behavior, Wiley International edition, ninth edition, John Wiley and Sons Inc, (2005), pp. 77.

[18] Schermerhorn, Introduction to Management, John Wiley and Sons-Asia, International Student Version, 10th edition,(2010), pp. 295.

[19] Sen Woo, Lee \& Tsai, Influence of Creativity and knowledge sharing on performance, Journal of Technology Management in China. 7(1)(2012), 64-77, https://doi.org/10.1108/17468771211207358

[20] Tan, Charleen \&Tee Ng, A Cirtical Reflection of Teacher Professionalism in Cambodia, policy and leadership studies academic group, National Institute of education, Nanyang Technological University, Republic of Singapore, 1(2)(2012), https://doi.org/10.1108/20463161211240106

[21] Wildy. Wallace, Professionalism, Portfolio and the Development of School Leaders, School and Leadership Management Journal, Research Library, 18(1)(1998), 123-140, https://doi.org/10.1080/13632439869817 